теме войны, которым не безразлична история страны, будущие поколения будут знать и помнить о Великой Отечественной войне и её героях.

$* * *$

1. Концепция патриотического воспитания граждан Российской Федерации. - М., 2003.

2. Электронный ресурс URL: https://news.rambler.ru/incidents/36826216-ot-kosmodemyanskoy-do-koenznamenitye-sovetskie-razvedchitsy/(дата обращения: 15.03.2021).

\title{
Бежанова Н...Л., Гаврилович Т.Г. \\ Критериальная характеристика проверки уровня сформированности знаний о картографических произведениях у учащихся третьего класса
}

ФГАОУ «Севастопольский государственный университет»

(Россия, Севастополь)

doi: 10.18411/lj-04-2021-133

\section{Аннотация}

В статье представлены критерии и показатели, а также критериальная характеристика проверки уровня сформированности знаний о картографических произведениях у учащихся третьего класса.

Ключевые слова: знания, критерии, показатели, критериальная характеристика, проверка, уровень сформированности, учащиеся третьих классов, картографические произведения.

Abstract

The article presents the criteria and indicators, as well as the criteria characteristic of testing the level of cartographic works knowledge formation among third-grade students.

Keywords: knowledge, criteria, indicators, criteria characteristics, test, formation level, third-grade students, cartographic works.

На современном этапе развития образования в Российской Федерации одной из главных задач является формирование знаний о картографических произведениях. На это указывают такие официальные документы, как Федеральный государственный образовательный стандарт начального общего образования (ФГОС НОО) [2], Примерная основная образовательная программа начального общего образования (ПООП НОО) [3], на основании которых разработаны учебно-методические комплексы (УМК), в которых подтверждается необходимость формирования знаний о картографических произведениях у учащихся третьего класса. Федеральный закон "Об образовании в Российской Федерации, определяет цель начального общего образования в виде «формирования личности обучающегося, развития его индивидуальных способностей, положительной мотивации и умений в учебной деятельности» [1]. Следовательно, формирования знаний о картографических произведениях учащихся третьего класса приобретает особую актуальность, поскольку обществу необходима функционально грамотная личность, способная адаптироваться к жизненным условиям и требованиям, рационально влияя на неё. От того, насколько успешно будут сформированы знания учащихся третьего класса, зависит дальнейшее обучение в школе. Представленная возрастная категория нами выбрана не случайно, так как именно в третьем классе учащиеся приобретают первоначальные знания о том, что такое ориентирование, карта, глобус, получают начальные знания о Солнечной системе, Земле и её движении.

Процесс изучения картографических произведений обладает очень важными учебно-воспитательными функциями: выступает основой, на которую накладываются все географические знания; картографические произведения развивают географическое мышление, образное восприятие пространства, раскрывает 
ассоциативный характер объективного мира; позволяют ощутить природную реальность и социальную картину изучаемой действительности, поэтому картографические произведения имеют неограниченные возможности для широкого применения в практической жизни; картографические произведения являются средством воспитания, идентифицируют уникальные и феноменальные свойства вмещающего пространства, развивает чувства ответственности, патриотизма и гражданственности [13, с.95].

А.Е. Дмитриев отмечает, что «знания раскрываются в педагогике как продукт познания людьми предметов и явлений действительности, законов природы и общества. Овладеть знаниями - значит усвоить факты, представления, понятия, законы той или иной науки. В знаниях находит обобщенное отражение объективная действительность. Признаками усвоения учеником знаний являются: понимание, осознание фактов, правил, понятий; готовность пересказать материал своими словами; формулирование правил, понятий; готовность приводить примеры для конкретизации выводов, обобщений; применение усваиваемых положений на практике» [7, с.11].

Проблему формирования знаний о картографических произведениях освещали в своих работах Г.Н. Аквилева, Н.Ф. Виноградова, Е.В. Григорьева, З.А. Клепинина, Т.С. Комиссарова, Е.Ф. Козина, И.Г. Омельянович, В.Д. Сухоруков, В.Г. Суслов и другие.

Т.С. Комиссарова о картографических произведениях в своей работе пишет, что «важность карты возрастает в связи с усилением ее роли как документа общения, отражающего уровень развития общества, его культуры и восприятия мира» [11, с.5]. Г.Н., Аквилева, 3.А. Клепинина считают, что знания картографических произведений, играют важную пропедевтическую роль на начальном этапе изучения естествознания. Без этих знаний почти невозможно усвоить материал соответствующей темы в курсе физической географии. Знакомство с планом и картой готовит детей к изучению географии в старших классах, где карта наряду с учебником выступает как важнейшее учебное пособие, по которому изучается распределение на Земле географических объектов и их номенклатура [9, с.67].

Н.Ф. Виноградова полагает, что картографические произведения - это «конкретные, наглядные факты и младший школьник легче воспринимает учебный материал. Для ребенка этого возраста отбираются только доступные, интересные и особенно динамичные факты, и их общее число не так велико. По мере развития ребенка, формирования его логического мышления количество знаний о явлениях окружающего мира постепенно увеличивается»[4, с.24].

И.Г. Омельянович раскрывает сущность формирования знаний картографических произведений в том, что «основной единицей географических знаний является понятие. Понятие - это форма мышления, отражающая существенные свойства, связи и отношения предметов и явлений; отражение в сознании сущности географических объектов, их наиболее характерных свойств, признаков, особенностей, связей, отношений между объектами. Понимание включает знание практического значения изученных объектов и явлений (понятий), для чего нужны знания о форме и движении Земли, о климатообразующих факторах и так далее» [12, с.1].

Д.Ю. Добротин полагает, что «уровень достижения планируемых результатов свидетельствует об усвоении опорной системы знаний, необходимой для продолжения образования на следующей ступени, на уровне осознанного произвольного овладения учебными действиями» [5, с.43].

Проведя анализ научно-методической литературы, нами выявлена существенная необходимость в формировании знаний о картографических произведениях. Однако, несмотря на это, нет чётко выявленных критериев и показателей поверки начального уровня сформированности знаний о картографических произведениях учащихся третьего класса, что и определило цель нашей статьи. 
Цель статьи - представить критериальную характеристику проверки начального уровня сформированности знаний о картографических произведениях учащихся третьего класса.

Для того чтобы составить критериальную характеристику необходимо выяснить, что такое критерий, показатель и уровневый показатель. Согласно толковому словарю русского языка под критериями мы будем понимать «признаки, на основании которых производится оценка, определение, классификация чего-либо» [14, с.115].

Под показателями мы будем понимать явления или события, по которым можно судить о ходе какого-нибудь процесса или уровне развития исследуемого признака [14, с.330]. Под уровнем мы будем подразумевать «степень, характеризующую качество, высоту, величину развития чего-нибудь» [14, с.405]

Анализ учебно-методических комплексов (УМК «Школа России», УМК «Начальная школа XXI века», УМК «Перспектива», УМК «Планета знаний») позволил нам выявить критерии проверки начального уровня сформированности знаний о картографических произведениях: знание о глобусе, знание о географической карте, знание о плане местности.

К данным критериям нами были подобраны показатели.

Таблий 1

Критерии и показатели сформированности знаний о картографических произведениях учашчихся третьего класса

\begin{tabular}{|c|c|}
\hline Критерии & Показатели \\
\hline Знание о глобусе & $\begin{array}{l}\text { - знание о модели земли; } \\
\text { - знание о вращении земли; } \\
\text { - знание понятий «параллели», «меридианы», «нулевой } \\
\text { меридиан», «экватор». }\end{array}$ \\
\hline Знание о географической карте & $\begin{array}{l}\text { - знание о горизонте и линии горизонта; } \\
\text { - знание об основных и промежуточных сторонах горизонта; } \\
\text { - знание понятий «географическая карта», «географические } \\
\text { объекты». }\end{array}$ \\
\hline Знание о плане местности & $\begin{array}{l}\text { - знание о плане; } \\
\text { - знание о масштабе; } \\
\text { - знание об условных обозначениях. }\end{array}$ \\
\hline
\end{tabular}

Система оценки предусматривает уровневый подход к представлению планируемых результатов и оценки их достижения [2]. Определённые нами критерии и показатели позволили выделить уровневые показатели проверки начального уровня сформированности знаний о картографических произведениях учащихся третьего класса.

Знание о глобусе.

Высокий уровень. Ученик дает правильный ответ, что глобус - это трехмерная уменьшенная модель Земли. Ребенок хорошо знает, что не видимая нам Земная ось, вокруг которой вращается Земля, наклонена. Ученик дает точное определение понятиям, что «параллели» - это линии, которые идут с запада на восток, «меридианы» - линии, которые идут с севера на юг, «нулевой меридиан» - воображаемая линия, которая делит наш земной шар на два полушария - Западное и Восточное, «экватор» линия, которая делит наш земной шар на два полушария - Северное и Южное.

Средний уровень. Ученик дает правильный ответ, что глобус - это трехмерная уменьшенная модель Земли. Ребенок хорошо знает, что не видимая нам Земная ось, вокруг которой вращается Земля, наклонена. Ученик путается в определении понятий, что «параллели» - это линии, которые идут с запада на восток, «меридианы» - линии, которые идут с севера на юг, но самостоятельно исправляет ошибки. Ребенок недостаточно хорошо знает, что «нулевой меридиан»- это воображаемая линия, 
которая делит наш земной шар на два полушария - Западное и Восточное, а «экватор» - линия, которая делит наш земной шар на два полушария - Северное и Южное.

Низкий уровень. Ученик дает правильный ответ, что глобус - это трехмерная уменьшенная модель Земли. Ребенок затрудняется ответить, что не видимая нам Земная ось, вокруг которой вращается Земля, наклонена. Ученик допускает ошибки и после наводящих вопросов учителя дает правильные определения понятиям, что «параллели» - это линии, которые идут с запада на восток, «меридианы» - линии, которые идут с севера на юг. Ребенок путается в определении, что «нулевой меридиан» - это воображаемая линия, которая делит наш земной шар на два полушария - Западное и Восточное, а «экватор» - линия, которая делит наш земной шар на два полушария Северное и Южное.

Знание о географической карте.

Высокий уровень. Ученик четко и правильно отвечает, что такое горизонт, что у него четыре основные стороны (север, юг, запад, восток) и безошибочно называет промежуточные стороны между ними. Ученик дает точное определение понятиям, что «географическая карта» - это плоская модель земли (уменьшенные изображения участков земной поверхности с помощью условных знаков), «географические объекты»- это все, что есть в окружающем мире (реки и моря, города и села, горы и долины, пустыни и джунгли).

Средний уровень. Ученик хорошо знает, что такое горизонт, что у него четыре основные стороны (север, юг, запад, восток), но путается, называя промежуточные стороны между ними. Ученик дает точное определение понятиям, что «географическая карта» - это плоская модель земли (уменьшенные изображения участков земной поверхности с помощью условных знаков), «географические объекты»- это все, что есть в окружающем мире (реки и моря, города и села, горы и долины, пустыни и джунгли).

Низкий уровень. Ученик с помощью наводящих вопросов от учителя отвечает, что такое горизонт. Ребенок путает основные стороны горизонта и затрудняется назвать промежуточные между ними. Ученик дает точное определение понятиям, что «географическая карта» - это плоская модель земли (уменьшенные изображения участков земной поверхности с помощью условных знаков), но путается в определении «географические объекты»- это все, что есть в окружающем мире (реки и моря, города и села, горы и долины, пустыни и джунгли).

Знание о плане местности.

Высокий уровень. Ученик дает четкий и правильный ответ, что план местности это точный чертёж местности, выполненный с помощью условных знаков и в определенном масштабе. Ребенок четко отвечает, что масштаб это отношение длины линий на карте к действительной длине и показывает, во сколько раз на плане уменьшены действительные расстояния. Ученик хорошо знает, что условные обозначения называются легендой и помещаются внизу карты, что их необходимо знать, чтобы находить на ней географические объекты, реки и моря, города.

Средний уровень. Ученик дает четкий и правильный ответ, что план местности это точный чертёж местности, выполненный с помощью условных знаков и в определенном масштабе. Ребенок недостаточно хорошо знает, что масштаб это отношение длины линий на карте к действительной длине и показывает, во сколько раз на плане уменьшены действительные расстояния. Ученик хорошо знает, что условные обозначения называются легендой и помещаются внизу карты, что их необходимо знать, чтобы находить на ней географические объекты, реки и моря, города.

Низкий уровень. Ученик самостоятельно не может дать ответ, что план местности - это точный чертёж местности, выполненный с помощью условных знаков и в определенном масштабе. Ребенок отвечает при помощи наводящих вопросов учителя, что масштаб это отношение длины линий на карте к действительной длине и показывает, во сколько раз на плане уменьшены действительные расстояния. Ученик недостаточно хорошо знает, что условные обозначения называются легендой и 
помещаются внизу карты, что их необходимо знать, чтобы находить на ней географические объекты, реки и моря, города.

Выше перечисленные данные позволили нам составить критериальную характеристику проверки начального уровня сформированности знаний о картографических произведениях у учащихся третьего класса.

Представим данную критериальную характеристику в таблице.

Таблииа 2

Критериальная характеристика сформированности знаний о картографических произведениях у учашихся третьего класса

\begin{tabular}{|c|c|c|c|}
\hline \multirow{2}{*}{ Критерии } & \multicolumn{3}{|c|}{ Уровневые показатели } \\
\hline & Высокий уровень & Средний уровень & Низкий уровень \\
\hline Знание о глобусе. & $\begin{array}{l}\text { Ученик дает правильный } \\
\text { ответ, что глобус - это } \\
\text { трехмерная } \\
\text { уменьшенная модель } \\
\text { Земли. Ребенок хорошо } \\
\text { знает, что не видимая } \\
\text { нам Земная ось, вокруг } \\
\text { которой вращается } \\
\text { Земля, наклонена. } \\
\text { Ученик дает точное } \\
\text { определение понятиям, } \\
\text { что «параллели»- это } \\
\text { линии, которые идут с } \\
\text { запада на восток, } \\
\text { «меридианы» - линии, } \\
\text { которые идут с севера на } \\
\text { юг, «нулевой меридиан» } \\
\text { - воображаемая линия, } \\
\text { которая делит наш } \\
\text { земной шар на два } \\
\text { полушария - Западное и } \\
\text { Восточное, «экватор» - } \\
\text { линия, которая делит } \\
\text { наш земной шар на два } \\
\text { полушария - Северное и } \\
\text { Южное. }\end{array}$ & $\begin{array}{l}\text { Ученик дает правильный } \\
\text { ответ, что глобус - это } \\
\text { трехмерная } \\
\text { уменьшенная модель } \\
\text { Земли. Ребенок хорошо } \\
\text { знает, что не видимая } \\
\text { нам Земная ось, вокруг } \\
\text { которой вращается } \\
\text { Земля, наклонена. } \\
\text { Ученик путается в } \\
\text { определении понятий, } \\
\text { что «параллели» - это } \\
\text { линии, которые идут с } \\
\text { запада на восток, } \\
\text { «меридианы» - линии, } \\
\text { которые идут с севера на } \\
\text { юг, но самостоятельно } \\
\text { исправляет ошибки. } \\
\text { Ребенок недостаточно } \\
\text { хорошо знает, что } \\
\text { «нулевой меридиан» - } \\
\text { это воображаемая линия, } \\
\text { которая делит наш } \\
\text { земной шар на два } \\
\text { полушария - Западное и } \\
\text { Восточное, а «экватор» - } \\
\text { линия, которая делит } \\
\text { наш земной шар на два } \\
\text { полушария - Северное и } \\
\text { Южное. }\end{array}$ & $\begin{array}{l}\text { Ученик дает правильный } \\
\text { ответ, что глобус - это } \\
\text { трехмерная уменьшенная } \\
\text { модель Земли. Ребенок } \\
\text { затрудняется ответить, } \\
\text { что не видимая нам } \\
\text { Земная ось, вокруг } \\
\text { которой вращается Земля, } \\
\text { наклонена. Ученик } \\
\text { допускает ошибки и } \\
\text { после наводящих } \\
\text { вопросов учителя дает } \\
\text { правильные определения } \\
\text { понятиям, что } \\
\text { «параллели» - это линии, } \\
\text { которые идут с запада на } \\
\text { восток, «меридианы» - } \\
\text { линии, которые идут с } \\
\text { севера на юг. Ребенок } \\
\text { путается в определении, } \\
\text { что «нулевой меридиан» } \\
\text { - это воображаемая } \\
\text { линия, которая делит наш } \\
\text { земной шар на два } \\
\text { полушария - Западное и } \\
\text { Восточное, а «экватор» - } \\
\text { линия, которая делит наш } \\
\text { земной шар на два } \\
\text { полушария - Северное и } \\
\text { Южное. }\end{array}$ \\
\hline $\begin{array}{c}\text { Знание о } \\
\text { географической } \\
\text { карте. }\end{array}$ & $\begin{array}{l}\text { Ученик четко и } \\
\text { правильно отвечает, что } \\
\text { такое горизонт, что у } \\
\text { него четыре основные } \\
\text { стороны (север, юг, } \\
\text { запад, восток) и } \\
\text { безошибочно называет } \\
\text { промежуточные } \\
\text { стороны между ними. } \\
\text { Ученик дает точное } \\
\text { определение понятиям, } \\
\text { что «географическая } \\
\text { карта»- это плоская } \\
\text { модель земли } \\
\text { (уменьшенные } \\
\text { изображения участков } \\
\text { земной поверхности с } \\
\text { помощью условных } \\
\text { знаков), } \\
\text { «географические }\end{array}$ & $\begin{array}{l}\text { Ученик хорошо знает, } \\
\text { что такое горизонт, что } \\
\text { у него четыре основные } \\
\text { стороны (север, юг, } \\
\text { запад, восток), но } \\
\text { путается, называя } \\
\text { промежуточные стороны } \\
\text { между ними. Ученик } \\
\text { дает точное определение } \\
\text { понятиям, что } \\
\text { «географическая карта» } \\
\text { - это плоская модель } \\
\text { земли (уменьшенные } \\
\text { изображения участков } \\
\text { земной поверхности с } \\
\text { помощью условных } \\
\text { знаков), } \\
\text { «географические } \\
\text { объекты»- это все, что } \\
\text { есть в окружающем мире }\end{array}$ & $\begin{array}{l}\text { Ученик с помощью } \\
\text { наводящих вопросов от } \\
\text { учителя отвечает, что } \\
\text { такое горизонт. Ребенок } \\
\text { путает основные стороны } \\
\text { горизонта и затрудняется } \\
\text { назвать промежуточные } \\
\text { между ними. Ученик дает } \\
\text { точное определение } \\
\text { понятиям, что } \\
\text { «географическая карта»- } \\
\text { это плоская модель земли } \\
\text { (уменьшенные } \\
\text { изображения участков } \\
\text { земной поверхности с } \\
\text { помощью условных } \\
\text { знаков), но путается в } \\
\text { определении } \\
\text { «географические } \\
\text { объекты» - это все, что }\end{array}$ \\
\hline
\end{tabular}




\begin{tabular}{|c|c|c|c|}
\hline & $\begin{array}{l}\text { объекты» - это все, что } \\
\text { есть в окружающем мире } \\
\text { (реки и моря, города и } \\
\text { села, горы и долины, } \\
\text { пустыни и джунгли). }\end{array}$ & $\begin{array}{l}\text { (реки и моря, города и } \\
\text { села, горы и долины, } \\
\text { пустыни и джунгли). }\end{array}$ & $\begin{array}{l}\text { есть в окружающем мире } \\
\text { (реки и моря, города и } \\
\text { села, горы и долины, } \\
\text { пустыни и джунгли). }\end{array}$ \\
\hline $\begin{array}{c}\text { Знание о плане } \\
\text { местности. }\end{array}$ & $\begin{array}{l}\text { Ученик дает четкий и } \\
\text { правильный ответ, что } \\
\text { план местности - это } \\
\text { точный чертёж } \\
\text { местности, выполненный } \\
\text { с помощью условных } \\
\text { знаков и в определенном } \\
\text { масштабе. Ребенок четко } \\
\text { отвечает, что масштаб } \\
\text { это отношение длины } \\
\text { линий на карте к } \\
\text { действительной длине и } \\
\text { показывает, во сколько } \\
\text { раз на плане уменьшены } \\
\text { действительные } \\
\text { расстояния. Ученик } \\
\text { хорошо знает, что } \\
\text { условные обозначения } \\
\text { называются легендой и } \\
\text { помещаются внизу } \\
\text { карты, что их } \\
\text { необходимо знать, чтобы } \\
\text { находить на ней } \\
\text { географические объекты, } \\
\text { реки и моря, города. }\end{array}$ & $\begin{array}{l}\text { Ученик дает четкий и } \\
\text { правильный ответ, что } \\
\text { план местности - это } \\
\text { точный чертёж } \\
\text { местности, } \\
\text { выполненный с } \\
\text { помощью условных } \\
\text { знаков и в определенном } \\
\text { масштабе. Ребенок } \\
\text { недостаточно хорошо } \\
\text { знает, что масштаб это } \\
\text { отношение длины линий } \\
\text { на карте к } \\
\text { действительной длине и } \\
\text { показывает, во сколько } \\
\text { раз на плане уменьшены } \\
\text { действительные } \\
\text { расстояния. Ученик } \\
\text { хорошо знает, что } \\
\text { условные обозначения } \\
\text { называются легендой и } \\
\text { помещаются внизу } \\
\text { карты, что их } \\
\text { необходимо знать, чтобы } \\
\text { находить на ней } \\
\text { географические объекты, } \\
\text { реки и моря, города. }\end{array}$ & $\begin{array}{l}\text { Ученик самостоятельно } \\
\text { не может дать ответ, что } \\
\text { план местности - это } \\
\text { точный чертёж } \\
\text { местности, выполненный } \\
\text { с помощью условных } \\
\text { знаков и в определенном } \\
\text { масштабе. Ребенок } \\
\text { отвечает при помощи } \\
\text { наводящих вопросов } \\
\text { учителя, что масштаб это } \\
\text { отношение длины линий } \\
\text { на карте к } \\
\text { действительной длине и } \\
\text { показывает, во сколько } \\
\text { раз на плане уменьшены } \\
\text { действительные } \\
\text { расстояния. Ученик } \\
\text { недостаточно хорошо } \\
\text { знает, что условные } \\
\text { обозначения называются } \\
\text { легендой и помещаются } \\
\text { внизу карты, что их } \\
\text { необходимо знать, чтобы } \\
\text { находить на ней } \\
\text { географические объекты, } \\
\text { реки и моря, города. }\end{array}$ \\
\hline
\end{tabular}

Таким образом, критериальная характеристика проверки начального уровня сформированности знаний у учащихся третьего класса включает в себя: критерии, показатели и уровневые показатели. Критериями будут являться:

— знание о глобусе (знание о модели земли; знание о вращении земли; знание понятий «параллели», «меридианы», «нулевой меридиан», «экватор»).

— знание о географической карте (знание о горизонте и линии горизонта; знание об основных и промежуточных сторонах горизонта; знание понятий «географическая карта», «географические объекты»);

— знание о плане местности (знание о плане; знание о масштабе; знание об условных обозначениях).

Дальнейшее направление работы видим в апробации данной критериальной характеристики и проверке начального уровня сформированности знаний о картографических произведениях учащихся третьего класса.

$$
* * *
$$

1. Федеральный закон от 29.12.2012 №273-Ф3 «Об образовании в Российской Федерации».

2. Федеральный государственный образовательный стандарт начального общего образования: проект [Текст]. - URL: https://regulation.gov.ru/projects\#npa=94553

3. Примерная основная образовательная программа образовательного учреждения начального общего образования. — URL: https://fgosreestr.ru/wp-content/uploads/2015/06/primernaja-osnovnajaobrazovatelnaja-programma-nachalnogo-obshchego-obrazovanija-1.pdf

4. Виноградова, Н.Ф. Окружающий мир. 3-4 кл. Методическое пособие. / Н.Ф. Виноградова. — 2-е изд. — Москва : ВЕНТАНА-ГРАФ , 2016. — 232 с. — Текст : непосредственный. 
5. Воробьева, С. В. Современные средства оценивания результатов обучения в общеобразовательной школе / С.В. Воробьева. — 2-е изд. — Москва : Юрайт, 2019. — 740 с. — Текст : непосредственный.

6. Добротин, Д.Ю. Методика преподавания предмета «Окружающий мир» / Д.Ю. Добротин. Москва : Юрайт, 2020. - 306 с. - Текст : непосредственный.

7. Дмитриев, А.Е. Дидактика начальной школы / А.Е. Дмитриев, Ю.А. Дмитриев. - 2-е изд. Москва : Юрайт, 2020. - 228 с. - Текст : непосредственный.

8. Загвязинский, В.И. Педагогический словарь / В.И. Загвязинский, А.Ф. Закирова, Т.А. Строкова. - Москва : Академия», 2018. - 352 с. - Текст : непосредственный.

9. Клепинина, 3.А. Методика преподавания предмета "Окружающий мир" / З.А. Клепинина, Г.Н. Аквилева, 2018,- Г, . — 5-е изд. - Москва : Академия, 2018. - 334 с. — Текст : непосредственный.

10. Козина, Е.Ф. Методика преподавания естествознания / Е.Ф. Козина. - 2-е изд. - Москва : Юрайт, 2020. - 256 с. - Текст : непосредственный

11. Комиссарова, Т.С. «Теоретические основы картографической подготовки учителя географии : специальность 13.00.02 «»: диссертация на соискание ученой степени доктора педагогических наук / Комиссарова Татьяна Сергеевна - 70 с. - Текст : непосредственный.

12. Омельянович / Омельянович, Г.И. — Текст : непосредственный // География. — 2017. — № 6. C. 10-13. http://www.academy.edu.by/files/podrazdelenia/geo/geograf\%20ponitie.pdf

13. Сухоруков, В.Д. Методика обучения географии / В.Д. Сухоруков, В.Г. Суслов. - Москва : Юрайт, 2018. - 359 с. - Текст : непосредственный.

14. Ушаков, Д. Н. / Д. Н. Ушаков. — Текст : электронный // : [сайт]. — URL: (дата обращения: 18.03.2021). http://slovari.yandex.ru/dict/ushakov

\section{Бородина Л.Н., Клименко Е.С., Рыченкова А.Ю. \\ К вопросу о подготовке отраслевых кадров в морских вузах на основе цифровизации образовательной среды}

ФГБОУ ВО «Государственный морской университет им. адм. Ф.Ф. Ушакова»

(Россия, Новороссийск)

doi: 10.18411/lj-04-2021-134

\section{Аннотация}

В статье рассматриваются вопросы цифровизации образовательной среды в процессе подготовки в морском вузе компетентных специалистов плавсостава для морского транспорта на примере изучения инженерной графики.

Ключевые слова: цифровая образовательная среда, морской вуз, информационные технологии, компетентность, специалисты для морского транспорта, инженерная графика.

\section{Abstract}

The article deals with the issues of digitalization of the educational environment in the process of training competent specialists of naval personnel for maritime transport in the maritime university by the example of studying engineering graphics.

Key words: digital educational environment, maritime university, information technology, competence, specialists for maritime transport, engineering graphics.

В настоящее время, в связи с общемировыми тенденциями совершенствования технологий и способов получения, обработки и передачи информации, открываются качественно новые возможности в сфере образования. Развитие информационных технологий, использование интернета, сетевое взаимодействие образовательных организаций, электронное обучение обуславливают необходимость изучения вопросов подготовки специалистов с учетом приоритетных направлений информатизации общества. В России определяющими цифровизацию документами являются Стратегия развития информационного общества в РФ на 2017-2030 годы [1], Программа «Цифровая экономика Российской Федерации» [2], в которых определены условия 